\title{
Design of a low-cost integrated Electrical Resistance Tomography(ERT) system based on serial bus
}

DOI:

10.1109/IST.2016.7738236

Document Version

Accepted author manuscript

Link to publication record in Manchester Research Explorer

\section{Citation for published version (APA):}

Wang, S., Liu, Y., Andrikopoulos, K., \& Yin, W. (2016). Design of a low-cost integrated Electrical Resistance Tomography(ERT) system based on serial bus. In IEEE Instrumentation \& Measurement Society IEEE. https://doi.org/10.1109/IST.2016.7738236

\section{Published in:}

IEEE Instrumentation \& Measurement Society

\section{Citing this paper}

Please note that where the full-text provided on Manchester Research Explorer is the Author Accepted Manuscript or Proof version this may differ from the final Published version. If citing, it is advised that you check and use the publisher's definitive version.

\section{General rights}

Copyright and moral rights for the publications made accessible in the Research Explorer are retained by the authors and/or other copyright owners and it is a condition of accessing publications that users recognise and abide by the legal requirements associated with these rights.

\section{Takedown policy}

If you believe that this document breaches copyright please refer to the University of Manchester's Takedown Procedures [http://man.ac.uk/04Y6Bo] or contact uml.scholarlycommunications@manchester.ac.uk providing relevant details, so we can investigate your claim.

\section{OPEN ACCESS}




\title{
Design of a low-cost integrated Electrical Resistance Tomography(ERT) system based on serial bus
}

\author{
Shupei Wang; Yuan Liu; Konstantinos Andrikopoulos; Wuliang Yin \\ School of Electrical and Electronic Engineering \\ University of Manchester \\ Manchester, UK \\ shupei.wang@postgrad.manchester.ac.uk \\ yuan.liu-5@postgrad.manchester.ac.uk \\ Konstantinos.andrikopoulos@student.manchester.ac.uk \\ Wuliang.Yin@manchester.ac.uk
}

\begin{abstract}
A low-cost integrated ERT system based on serial bus and 2 evaluation boards with 8 electrodes is designed and implemented. Tikhonov regularization is adopted for image reconstruction with conductance values measured from the designed system. Test results suggest that the system can produce reliable and repeatable measurements for image reconstructions of multiple objects with the cost lower than 100 GBP. Comparisons between the proposed low-cost system and commercial ERT system are also implemented to conclude the advantages and drawbacks of the proposed system.
\end{abstract}

Keywords-Electrical Resistance Tomography; ERT system; low-cost; serial bus; impedance analyzer

\section{INTRODUCTION}

Electrical Resistance Tomography (ERT) is a popular process monitoring technique in industrial applications and there are numerous aqueous-based processes to which ERT is suited[1]. The aim of ERT is to reconstruct the conducting (or dielectric) properties of an object from ERT measurements of electrical signals, taken from all possible views of the sensing electrodes[2]. It involves imaging internal material distribution with relatively low cost and fast imaging speed. The basic principle is to acquire boundary voltages from sensors (electrodes) located on the periphery of an object, such as a process vessel, pipeline, etc.[3, 4] A typical ERT system consists of three parts, a process vessel (with electrodes attached on the inner surface), a data acquisition system and a host computer, as shown in Figure1.

Although ERT has a relatively low-cost, the price per system is still normally $£ 20,000$, which limits wider adoption of this technique. In the present design, with the application of a serial bus based impedance analyzer and a switch board, the total cost of an ERT system can be lowered to approximately $£ 100$ excluding the host PC and software costs.

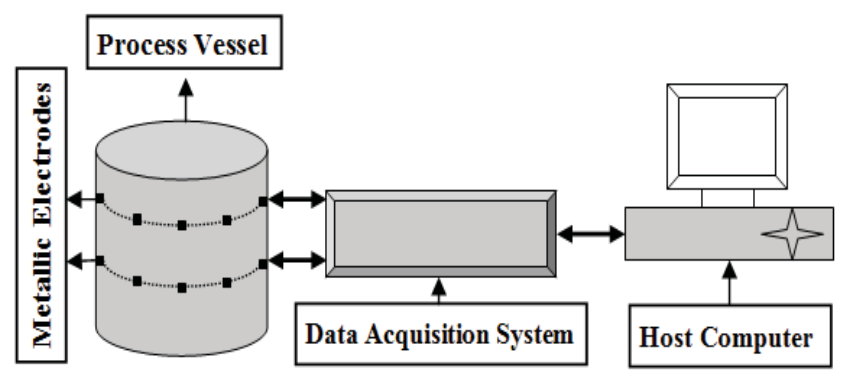

Figure1.An example of typical ERT system

The scope of this paper includes the process of designing the system with 2 evaluation boards and the comparison between the lost-cost system and commercial ERT system. Signal-to-Noise Ratio (SNR) is tested to prove the stability and repeatability of the system. Some real tests of multiple objects and different materials with corresponding image reconstructions are also presented to verify the capability and accuracy of the system.

\section{SYSTEM DESIGN AND COMPARISON}

\section{A. Core components and system structure}

An integrated impedance analyser chip AD5933 was adopted as the major data acquisition component (Figure 2). 


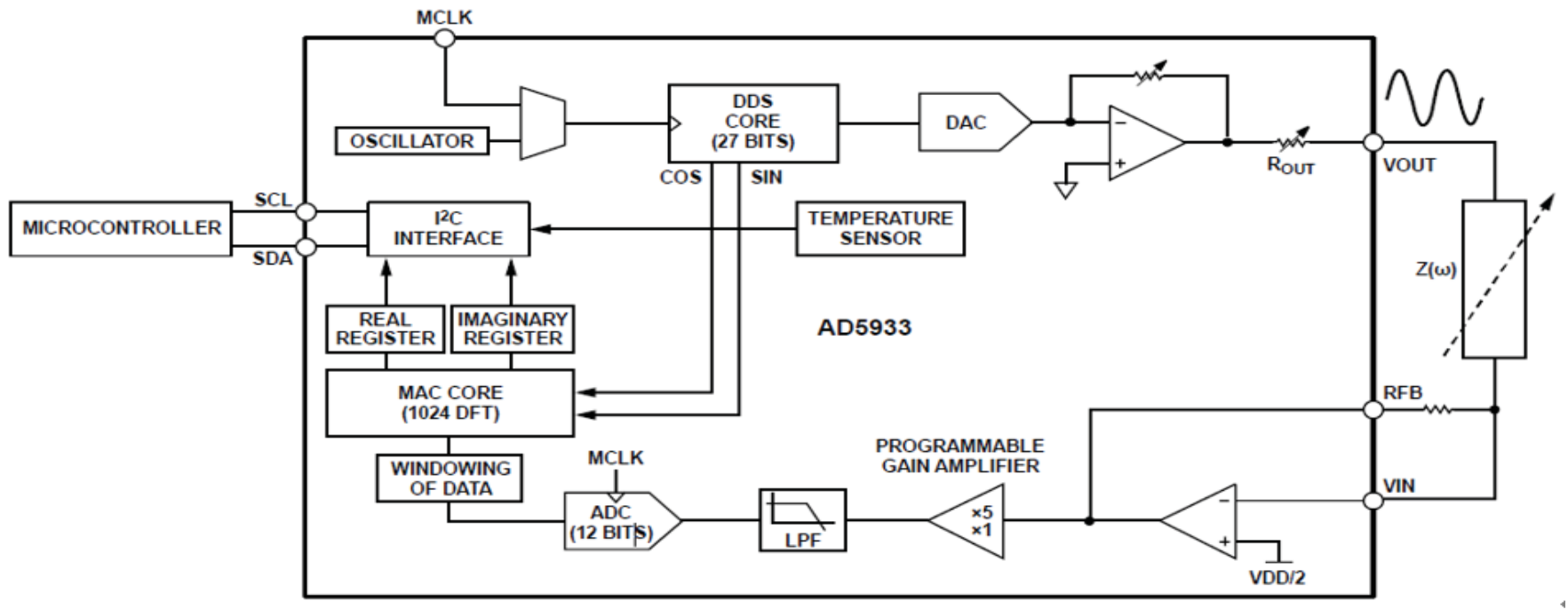

Figure 2.Block diagram of AD5933

Above figure is the block diagram of AD5933 and the object to be measured is placed between electrodes $V_{\text {out }}$ and $V_{\text {in }}$. The chip consists of three functional stages: voltage excitation stage (DDS core, DAC and amplifier), current measurement stage (current to voltage converter, programmable gain amplifier, low pass filter and 12 bits ADC) and the Discrete Fourier Transform stage (MAC core, real and imaginary register)[5].

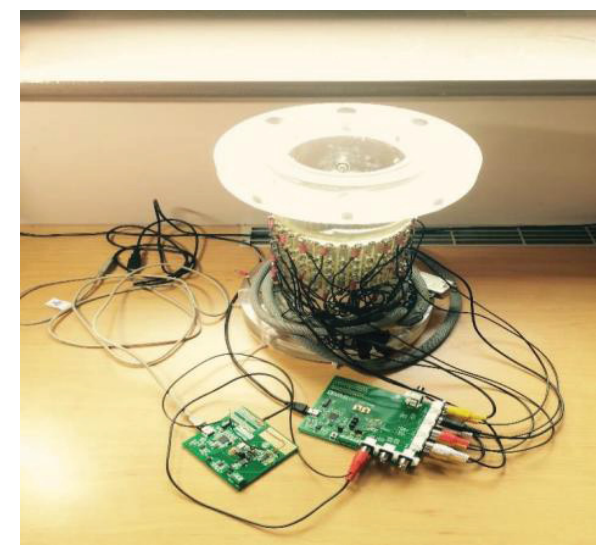

Figure 3. Prototype of the designed system
The output data from AD5933 is the complex impedance of the target, including frequency, phase angle, amplitude, real and imaginary parts of impedance. In the case of ERT, the real part component of the measured impedance will be used.

AD5933 has a serial bus interface $\left(\mathrm{I}^{2} \mathrm{C}\right)$. Another chip ADG2188 which has the same serial bus interface is used as the switching circuit in order to accomplish the measurements with certain strategy. ADG2188 provides an 8 by 8 switch matrix. 8 input ports on the ADG2188 (Y0 Y7) are connected to the 8 ERT electrodes distributed evenly on the periphery of the target cylindrical vessel and 2 ports (X0\&X1) are connected to the $V_{\text {out }}$ and $V_{\text {in }}$ electrodes of AD5933. The Inner diameter of the vessel is about $10.2 \mathrm{~cm}$.

Based on the chips selected, a tomography system including process vessel, data acquisition system and host computer is built (Figure 3). To simplify the experiment, corresponding evaluation boards of AD5933 and AD2188 was used for quick prototyping.

Both evaluation boards are connected to a host computer through USB interface so as to be controlled and programmed through corresponding software via $I^{2} C$ serial bus. The simplified structure map is shown in Figure 4.

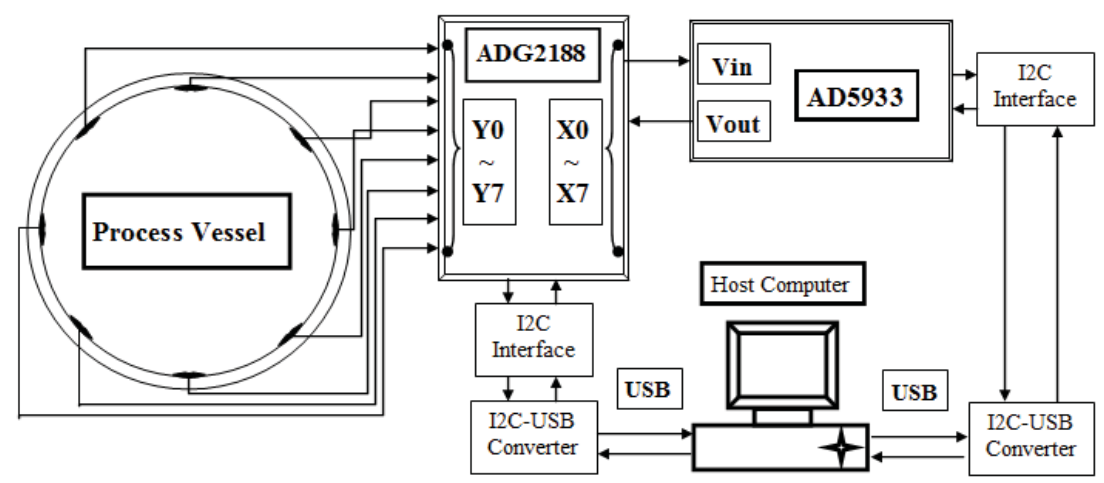

Figure 4.Simplified block diagram of the system 


\section{B. System comparison}

In order to achieve a comprehensive view of the difference between the proposed system and commercial ERT system, statistic comparisons are carried out in Table 1.

The capabilities of the proposed system can be indicated from the provide information, however, several major drawbacks listed below should be taken into consideration when the system is adopted in real applications:

1) Due to the lack of source code provided by the chip manufacturer, there is no corresponding software kit developed specificly for ERT measurement. All the measurements in the present paper are taken and recorded manually.

2) Additional circuitry needs to be developed if the number of electrodes increases because ADG2188 is only capable for 8-electrode measurement.

3) When the overall conductance of the ERT plane varies in a relatively large range, the result taken by the system might be distorted because of the lack of calibration. This will be explained in latter sections.

Table 1. Statistic comparison between proposed system and commercial ERT system

\begin{tabular}{|c|c|c|}
\hline & AD5933+ADG2188 & $\begin{array}{c}\text { Example of Commercial } \\
\text { ERT System }\end{array}$ \\
\hline Estimated Cost (GBP) & f100 & $f 20,000$ \\
\hline $\begin{array}{l}\text { Commutation } \\
\text { Interface }\end{array}$ & Serial I2C & $\begin{array}{c}\text { RS-232c / or USB } \\
\text { converted virtual port }\end{array}$ \\
\hline Excitation & Voltage VDD $=3.3 \mathrm{~V}$ & $\begin{array}{c}\text { Current } 0-1.5,-15,- \\
75 \mathrm{~mA}(256 \text { steps })\end{array}$ \\
\hline Phase Measurement & Yes & Yes \\
\hline $\begin{array}{c}\text { Complex Impedance } \\
\text { Measurement }\end{array}$ & Yes & Yes \\
\hline $\begin{array}{l}\text { Number of } \\
\text { Electrodes }\end{array}$ & 8 & 128 \\
\hline System Accuracy & $\pm 0.5 \%$ & $\pm 0.5 \%$ \\
\hline $\begin{array}{l}\text { Injection Current } \\
\text { Frequency Range }\end{array}$ & $1 \mathrm{~Hz}-100 \mathrm{kHz}$ & $\begin{array}{c}75 \mathrm{~Hz}-\begin{array}{l}153.6 \mathrm{kHz}(12 \\
\text { steps })\end{array} \\
\end{array}$ \\
\hline $\begin{array}{l}\text { Maximum system } \\
\text { clock frequency }\end{array}$ & 16.776MHz & $22.1184 \mathrm{MHz}$ \\
\hline ADC Resolution & 12 bits & 12 bits \\
\hline Impedance Range & $\begin{array}{c}1 \mathrm{k} \Omega-10 \mathrm{M} \Omega \\
\text { (capable of } 100 \Omega- \\
1 \mathrm{k} \Omega \text { with } \\
\text { additional } \\
\text { circuitry) }\end{array}$ & $\mathrm{NaN}$ \\
\hline $\begin{array}{c}\text { Peak to Peak Voltage } \\
\text { Range }\end{array}$ & $\begin{array}{l}0.198 \mathrm{~V}-1.98 \mathrm{~V}(4 \\
\text { steps })\end{array}$ & $\pm 10 \mathrm{~V}$ \\
\hline Measuring Speed & Manual & $\begin{array}{c}3 \text { frames/ S (16 } \\
\text { electrodes per plane) } 15 \\
\text { frames/S ( } 8 \text { electrodes } \\
\text { per plane) }\end{array}$ \\
\hline Software Kit & Limited & Yes \\
\hline
\end{tabular}

\section{REAL TESTS AND RESULTS}

Groups of ERT measurements are carried out and corresponding reconstructed images are also listed in order to inspect the performance of the system.

\section{A. Measurement Strategy}

The measurement strategy adopted in the designed system is reciprocal adjacent strategy. Conventional reciprocal adjacent strategy is implemented by exciting a pair of adjacent electrodes with a source/sink alternating current and measuring voltages across all other adjacent electrode pairs with repeated measurements omitted[6]. For an $N$ electrode ERT system, the number of projections to be measured is $N(N-3) / 2[1]$. As for the designed system, the input and output are voltage and the impedance under the projection of two activated electrodes can be measured directly, which makes the measurement pattern similar to that of Electrical Capacitance Tomography (ECT) and the number of measurements taken is $N^{*}(N-1) / 2$ [7]. The quality of reconstructed images would certainly benefit from the increased number of measurements comparing to conventional ERT measurement strategy as more information will be provided for inverse calculation. The increased number of measurements in a full ERT measurement is $N$.

\section{B. Measurement Process}

It is necessary to calibrate the AD5933 evaluation board to achieve precise measurements. The basic idea is to choose the proper calibration resistor and feedback resistor according to estimated impedance range of the target. The specifications are provided in AN1252[8].

After the selection of two resistors mentioned above, the tomography system is configured and ready for measurements. Before the ERT measurements are taken, signal-to-noise ratio (SNR) is tested to verify the stability of the system.

As for the ERT measurements, reference conductance values are recorded under the chosen measurement strategy when the vessel is filled with tap water. Afterwards other groups of conductance values will be measured with different objects placed into the vessel.

\section{Image Reconstruction}

The sensitivity matrix used in the image reconstruction process is acquired from an ideal simulated 2D model designed in Ansys Maxwell (Figure 5).

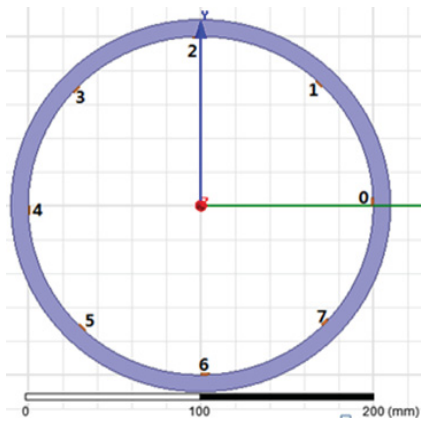

Figure 5. Ansys Maxwell model of the system 
The fundamental equation adopted for calculating sensitivity is[9]:

$$
S_{j, k}=-\int E_{\varphi} * E_{\psi} d a \approx-E_{\varphi} * E_{\psi}
$$

Where $S_{j, k}$ is the sensitivity of the $k$ th pixel under projection $j(j \in\{1,2, \ldots 28\}), E_{\varphi}$ and $E_{\psi}$ are the electric field strengths inside the pixel when the two electrodes under one projection are excited separately.

Hence, the sensitivity matrix can be presented as:

$$
J_{28 * N}=\left[\begin{array}{cccc}
S_{1,1} & S_{1,2} & \cdots & S_{1, N} \\
S_{2,1} & S_{2,2} & \cdots & S_{2, N} \\
\vdots & \vdots & \ddots & \vdots \\
S_{28,1} & S_{28,2} & \cdots & S_{28, N}
\end{array}\right]
$$

Where $N$ is the chosen number of pixels.

In the inverse calculations, Tikhonov regularization is employed to avoid over-fitting due to ill-conditioning and sharpen the images. But because of the convergent nature of regularization, the solutions of inverse problem will be converged to the reference level. The mathematical formula is[10]:

$$
\vec{\sigma}=\left(J^{T} J+\mu I\right)^{-1} J^{T} \vec{V}
$$

Where $\vec{\sigma}$ is the conductivity vector, $J$ and $J^{T}$ are the sensitivity matrix and its transposed form, $I$ is an identity matrix, $\mu$ is known as the regularization parameter and $\vec{V}$ is the vector of measured voltages in conventional ERT. In the present system, it will be replaced with the vector of measured conductance.

\section{RESUlTS}

\section{A. Signal-to-Noise Ratio (SNR)}

The formula for calculating SNR is[11]:

$$
S N R_{d B}=20 \log _{10} \frac{\text { Signal }_{R M S}}{\text { Noise }_{R M S}}
$$

Where Signal $_{R M S}$ and Noise $R M S$ are the root mean square values of signal and noise.

When the vessel is filled with tap water, 100 measurements are repeated with each electrode pair. The standard deviation value of each 100 measurement is considered to be the noise value. Hence the average SNR of the 28 'passages' formed by all possible electrode pairs can be calculated. The results are shown in Figure 6.

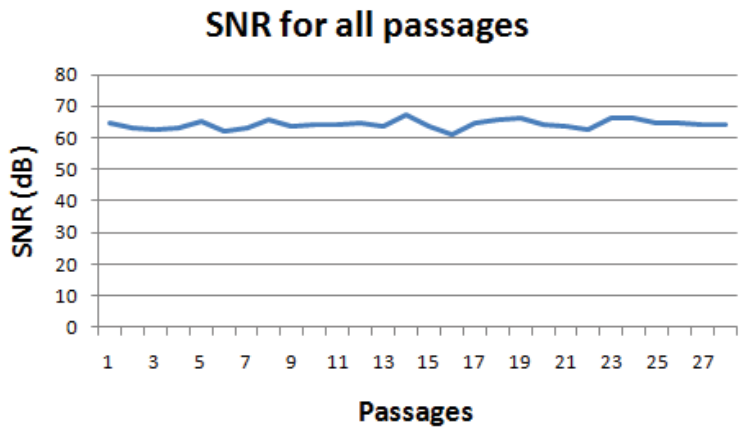

Figure 6.SNR for all passages
The overall SNR level of the system stays between 60 $\mathrm{dB} \sim 70 \mathrm{~dB}$, which indicates that the stability of the present system can satisfy industrial requirements.

\section{B. Reference Conductance}

Figure 7 shows the measured conductance of reference water under each projection. Those values form a continuous $\mathrm{U}$ curve, which can indicate the relative distance between the transmitter and receiver electrode of each projection.

\section{Reference Conductance}

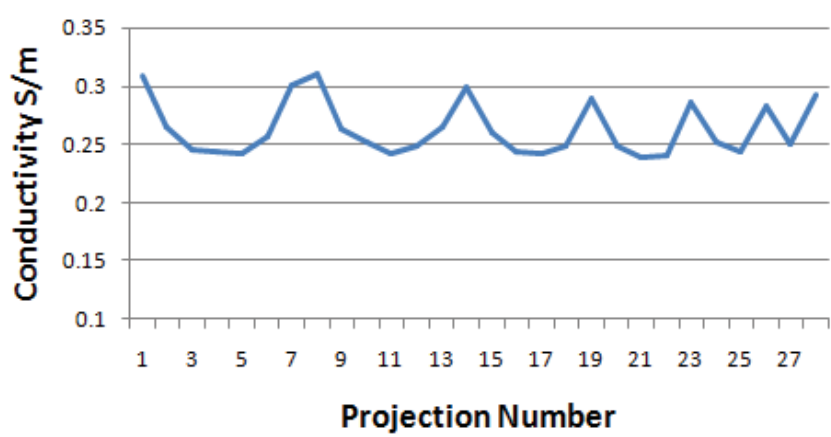

Figure 7. Reference conductance curve

When an object with different conductivity is placed into the vessel, the conductance measurements will vary correspondingly with the change in overall conductivity distribution (Figure 8).

\section{Conductance with Object in Vessel}

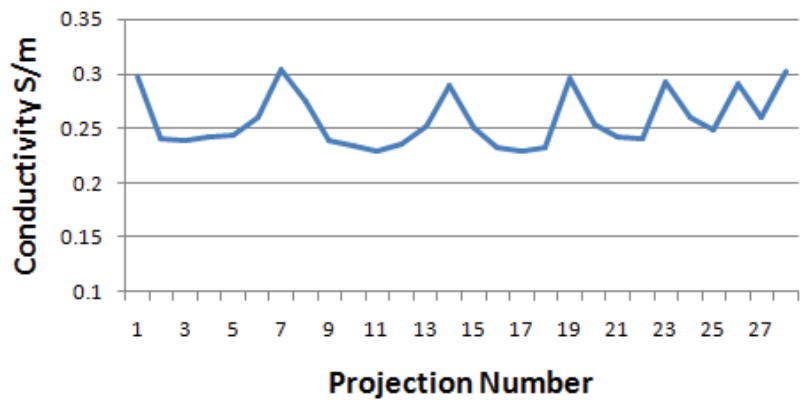

Figure 8. Conductance with object in vessel

\section{Image reconstruction}

In following experiments, objects of different materials, quantities and positions are placed into the vessel to test the feasibility and effectiveness of the designed system.

In Figure 9, 4 groups of images with single object are presented. In each group, the actual position and material of the objects are compared with their corresponding reconstructed images. In groups 1 and 2, a cylindrical metallic bar with the diameter of $3.81 \mathrm{~cm}$ is placed in two different positions inside the vessel. Groups 3 and 4 are the cases of a non-conductive wooden bar with the same diameter. 


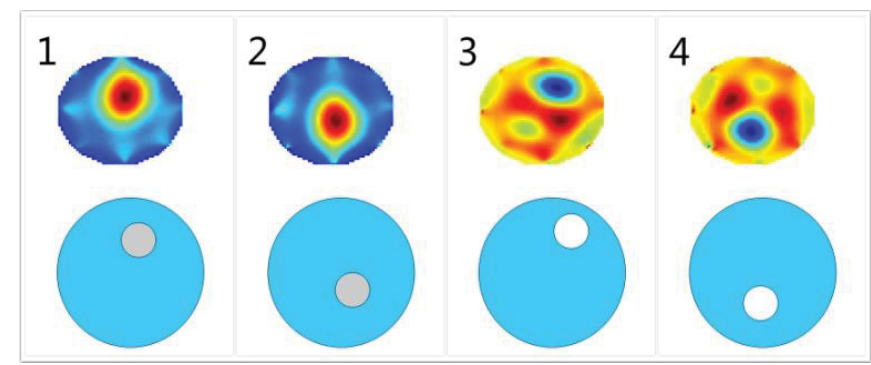

Figure 9. Single object image reconstruction

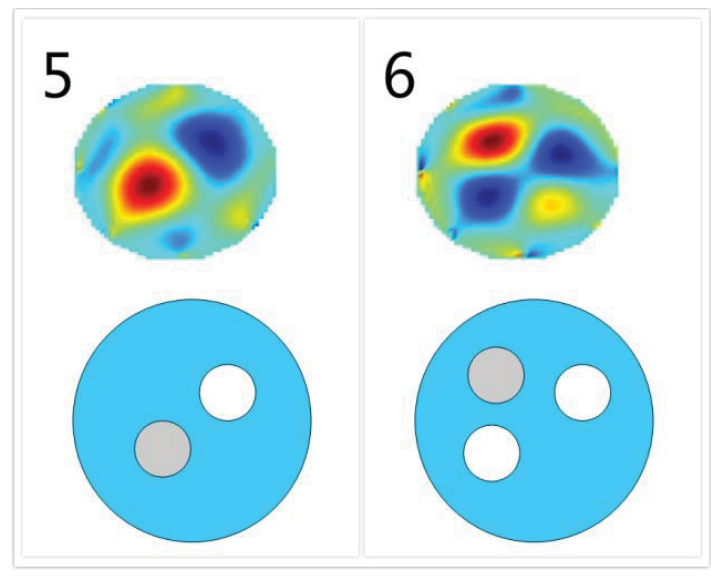

Figure 10. Multiple objects image reconstruction

In Figure 10, group 5 shows the result of two objects with the same diameter placing in the vessel while one of them is metallic and the other is non-conductive. Group 6 shows the corresponding image from a group of one metallic and two non-conductive bars.

We can indicate from the results that the designed system performs well on single object detection, as the position and boundary of the object can be identified from the reconstructed images, which alternatively proves the capability of the design and operation principles. As for the results of multiple objects, the boundaries and locations of the targets can be clearly identified while several unwanted spikes and shades still exist. As the insufficient amount of electrodes which leads to inadequate information for image reconstruction, we can certainly expect higher accuracy if we increase the number of electrodes in future experiments.

\section{CONCLUSION}

A low cost integrated ERT system based on serial bus is proposed. It is based on an impedance analyser core and a switch circuit. Moreover, the system adopts an analogous ECT measurement strategy for 8 electrodes and Tikhonov regularization for image reconstruction. The whole measurement process is fulfilled by vibrating and measuring the impedance with the impedance analyser while operating the switch board on a host computer. Reconstructed images indicate accurate and stable performance of the system and the total cost is reduced by approximately 200 times comparing to existed commercial ERT systems.

As the main drawback of promoting commercial ERT system is the relatively high cost, the authors believe the designed system has significant potentials in the market which can popularize ERT into many applications especially those require large quantity of lower cost and relatively less accurate ERT systems. However, source codes of the evaluation boards needs to be provided in future works in order to develop software kits for automatic measures.

\section{REFERENCES}

1. Dickin, F. and M. Wang, Electrical resistance tomography for process applications. Measurement Science and Technology, 1996. 7(3): p. 247.

2. Mann, R., et al., Application of electrical resistance tomography to interrogate mixing processes at plant scale. Chemical engineering science, 1997. 52(13): p. 2087-2097.

3. M.S.Beck, Process Tomography: Principles, Techniques and Applications. 1995: ButterworthHeinemann Ltd.

4. Scott, D.M., Process Imaging For Automatic Control. 2005: Taylor\&Francis Group.

5. Devices, A., Evaluating the AD5933 1 MSPS, $12-$ Bit Impedance Converter Network Analyzer, A. Devices, Editor. 2012.

6. Holden, P., et al., Imaging stirred - vessel macromixing using electrical resistance tomography. AIChE Journal, 1998. 44(4): p. 780790.

7. W.Q. Yang, D.M.S., T.A. York and H. McCann, An image-reconstruction algorithm based on Landweber's iteration method for electricalcapacitance tomography. Meas. Sci. Technol., 1999. 10: p. 1065-1069.

8. Usach, M. How to Configure the AD5933/AD5934. 2013. AN1252.

9. Murai, T. and Y. Kagawa, Electrical impedance computed tomography based on a finite element model. Biomedical Engineering, IEEE Transactions on, 1985(3): p. 177-184.

10. Holder, D.S., Electrical Impedance Tomography: Methods, History and Applications. 2004: CRC Press.

11. Olaf Dietrich, J.G.R., Scott B. Reeder, Maximilian F. Reiser and Stefan O. Schoenberg, Measurement of signal-to-noise ratios in MR images: Influence of multichannel coils, parallel imaging, and reconstruction filters. Journal of Magnetic Resonance Imaging, 2007. 26(2): p. 375-385. 